\title{
INVESTIGATION OF EFFECT OF FRICTION STIR DRILLING PARAMETERS ON ELASTOPLASTIC BEHAVIOUR OF AL ALLOY
}

\author{
VISHWANATH K. C. ${ }^{1} \boldsymbol{\&}$ THIRTHA PRASADA H. P. ${ }^{2}$ \\ ${ }^{1}$ Research Scholar, VTU-RRC, Belgaum, Department of Mechanical Engineering, Rajarajeswari College of Engineering, \\ Bangalore, Karnataka, India \\ ${ }^{2}$ Associate Professor, VTU-CPGS, Muddhenahalli, Chikkaballapur(D), Karnataka, India
}

\begin{abstract}
The aim of the research work was to investigate on the effect of drilling parameters on ultimate tensile strength of holed specimen. The specimen tested for study to determine the UTS for both conventionally drilled hole and frictional expanded hole. The thickness of the plate, taper drill angle, lubrication rate, feed and drill speed increase the pressure and temperature of the work piece is optimized using Taguchi technique. ANOVA shows feed rate, tool rotation speed and thicknesses of plate are the most influenced parameters.
\end{abstract}

KEY WORDS: Notch Deformation, Friction Stir Drilling, Notch Strain, Notch Stress \& Aluminium Alloys

Received: Dec 12, 2017; Accepted: Jan 02, 2018; Published: Feb 01, 2018; Paper Id.: IJMPERDFEB2018126

\section{INTRODUCTION}

Some new technologies increase the strength and the fracture toughness of the materials by refining the grain boundaries. In this context, many research works focused to develop high toughness and lower stress concentration techniques by experimental methods, but only few or no works investigated on elasto-plastic behaviour of aluminium [1-3]. It is well known that the fasteners are structural components where the cracks are nucleated which leads to failed the components. To overcome this issue, the compressive residual stress is induced around the hole which suppresses the cracks propagation. One of the promising technique to increase the hole life is based on fining the grain boundaries on the surface of materials. This surface modification could be carried out by severe plastic deformation (SPD) with various techniques [4-6].

The SPD forming introduces ultra-fine grain boundary with larger plastic strain into a bulk alloys, which leads to an increase in high specific strength components. There are many techniques for SPD such as tensional, equal channel angular pressing etc. The torsion straining technique is used to improve surface hardness of the materials. Many researchers have tried to modify for enhancing the hole strength. Few researchers developed mandrel modified surface of hole with torsion. Hole surface modification method was applied to improve the fastener holes of the aircraft structure. One of the promising methods is friction stir hole expansion (FSHE) to produce ultrafine microstructural modification of the surface of the hole. The objective of the work is to investigate the material structure and mechanical property relation for FSHE process for Al6061 alloy.

\section{EXPERIMENTAL STUDY}

The FSHE specimens were cut from Al 6061 alloy sheet along longitudinal axes i.e means along the rolling direction. The specimen prepared according to ASTM E466 07 is as shown in Figure 1 with centralhole diameter of 
$9.8 \mathrm{~mm}$. The FSHE tools were prepared with three different tapering to obtain final $10 \mathrm{~mm}$ diameters. Three feed rate and three cutting speeds were selected to produce larger interference fit between the hole and mandrill as shown in Figure 2. The interference creates larger torsional force, frictional heat and poor surface quality. The FSHE specimens determine the tensile properties using universal testing machine. The specimen was fixed on the UTM. The UTM loading was done gradually via the computer software. As the load was being applied, the microstrain readings were noted down corresponding to the respective loads, from the strain indicator. A strain gauge was mounted on the specimen at the vicinity of the notch root, as the mounting of the strain gauge exactly at the notch root was difficult owing to very small width of the plate and curvature of the notch.

Design of Experiment was used to plan the experiment, so that approximate data which can be analyzed by statistical method will be collected, resulting in valid and objective conclusion. The control factors showed in Table 1 includes three different levels of thickness of plate, Tool Taper angle, lubrication rate, Feed rate and Tool rotational speed used as combination in formulation of FSHE process parameters.

Table 1: Factors and Levels in the Formulation of FSHE Parameters

\begin{tabular}{|c|l|c|c|c|c|}
\hline \multirow{2}{*}{ Sl. No. } & \multirow{2}{*}{ Factors } & \multirow{2}{*}{ Unit } & \multicolumn{3}{|c|}{ Levels } \\
\cline { 4 - 6 } & & & $\mathbf{1}$ & $\mathbf{2}$ & $\mathbf{3}$ \\
\hline 1 & Thickness of plate & $\mathrm{mm}$ & 4 & 5 & 6 \\
\hline 2 & Tool Taper angle & $\circ$ & 72 & 76 & 80 \\
\hline 3 & Lubrication rate & $\mathrm{cm} 3 / \mathrm{m}$ & 0.5 & 0.75 & 1 \\
\hline 4 & Feed rate & $\mathrm{mm} / \mathrm{min}$ & 2 & 4 & 6 \\
\hline 5 & Tool rotation speed & $\mathrm{rpm}$ & 500 & 800 & 1100 \\
\hline
\end{tabular}

For this investigation, an orthogonal array was selected which could accommodate five factors, each at three variability levels. This accommodation was possible in the feature "Three Level Design" in MINITAB wherein it was decided to select a $\mathrm{L}_{27}$ array with five factors at three levels.

\section{RESULTS AND DISCUSSIONS}

The microstructure of FSHE hole for different process parameters is shown in Figure 1. The changes in grain size and grain orientation were due to the FSHE. Microstructure of the hole surface at three different locations, starting, middle and ending were obtained. The location showed the effect of the first point in the process. The micrograph presents the orientation and texturing of the grains along the forming direction. Also, fragmentation of the relatively larger sized particles present in the raw material presented elongated streaks. Observation of the microstructure shows the presence of un dissolved large and fine grain particles without grain orientation.
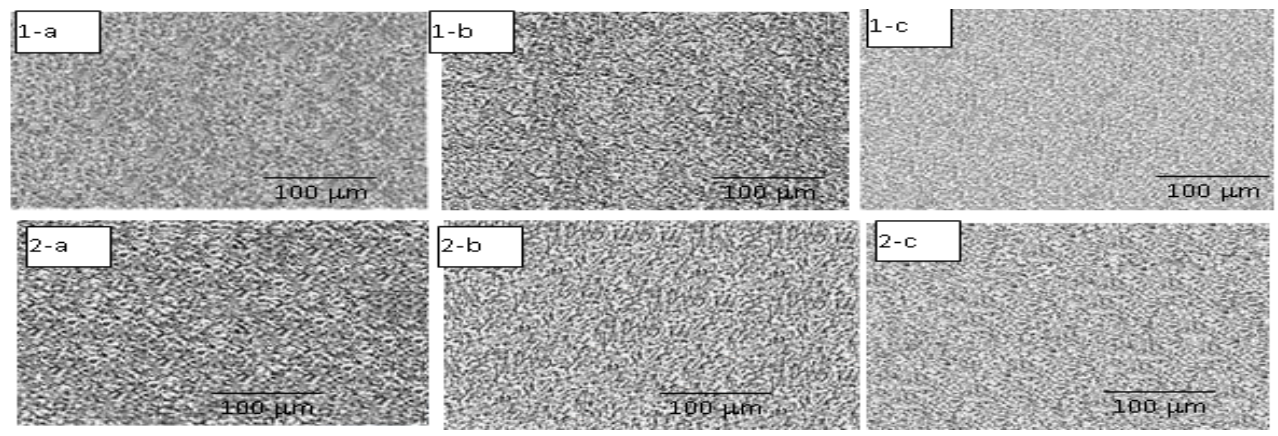

Figure 1: Microstructure of FSHE Specimens 1- $76^{\circ}$ Tapper Angle and 2- $80^{\circ}$ Tapper Angle ( a- Entrance, bMiddle and c-End of the Specimens) 


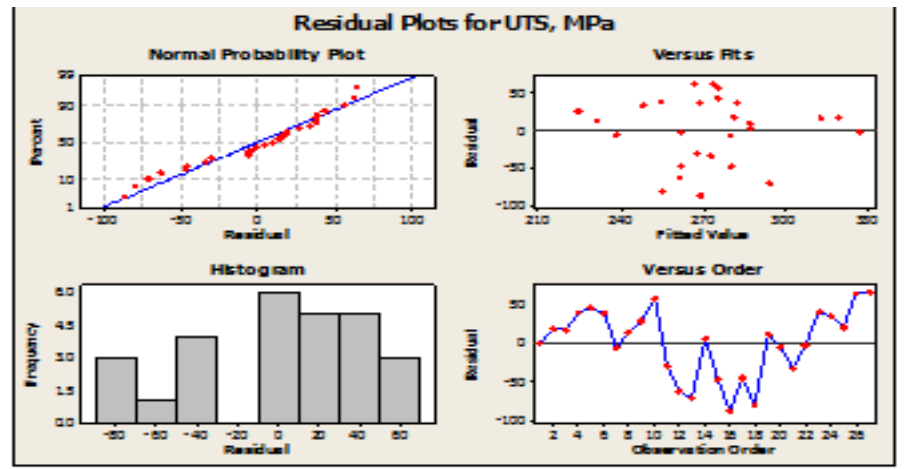

Figure 2: Normal Probability Plot for UTS of Drilled Hole Specimens

Normal probability plots for the roughness which was obtained from MINITAB V-16 are shown in Figure 2. The roughness was found to be equally distributed along the trend line of a normal probability plot. Hence, the process was said to be stable.

The range of UTS in Figure 3 over the three levels of each experimental factor, was: for thickness of plate (A) 4 $\mathrm{mm}$, for tool diameter (B) $72{ }^{\circ}$ for taper angele (C) $0.75 \mathrm{~cm}^{3}$ lubrication (D) $2 \mathrm{~mm} / \mathrm{min}$ feed rate and for tool rotation speed (E) $800 \mathrm{rpm}$. In particular, factor A (1), factor B (1), factor C (2), factor D (1) and factor E (2) contributed for maximun UTS combinations.

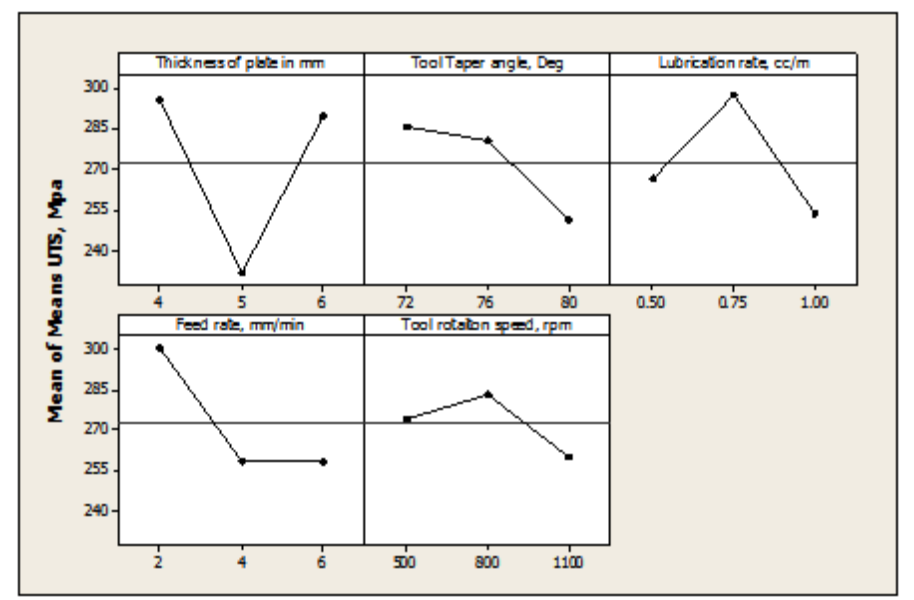

Figure 3: Effect of FSHE Process Parameters on UTS of Drilled Hole Specimens

For factor $\mathrm{A}$, level 1 maximized the average hardness and the $\mathrm{S} / \mathrm{N}$ ratio. The factor $\mathrm{B}$, factor $\mathrm{C}$, factor $\mathrm{D}$ and factor $\mathrm{E}$ is as same as that of factor A. Hence B1, C2, D1 and E2 levels were selected for optimum value.

Results suggest that the optimum condition for maximum hardness was the combination of A1B1C2D1E2 levels of the respective control factors. This implied that in order to increase the hardness, thickness of sheet and tool diameter should be lowered, while the feed rate must be decreased. 
Table 2: Fisher's Values (F) for all Control Factors

\begin{tabular}{|c|c|c|c|c|c|c|}
\hline Factors & DOE & Sum of Squares & Mean Squares & $\mathbf{F}_{\text {cal }}$ & $\mathbf{F}_{\text {tab }}$ & \% of Contribution \\
\hline A & 2 & 442.7 & 221.35 & 16.20 & 3.63 & 39.49 \\
\hline B & 2 & 95.05 & 47.52 & 3.48 & 3.63 & 8.48 \\
\hline C & 2 & 184.75 & 92.37 & 6.76 & 3.63 & 16.48 \\
\hline D & 2 & 149.97 & 74.98 & 5.49 & 3.63 & 13.38 \\
\hline E & 2 & 29.91 & 14.98 & 1.09 & 3.63 & 2.67 \\
\hline Error & 16 & 218.59 & & & & \\
\hline Total & $\mathbf{2 6}$ & $\mathbf{1 1 2 0 . 9 7}$ & & & & \\
\hline
\end{tabular}

Examination of the calculated Fisher's values (F) for all control factors also shows a high influence and low influence factors on the \% thickness reduction as shown in Table 2. the $\mathrm{F}_{\text {cal }}$ value was calculated for each design parameter. The optimum test conditions were estimated from the significant factors. The computed value of $F_{\text {cal }}(6.76)$ was more than that from statistical $F_{\text {tab }}(3.63)$ value. $F_{\text {tab }}$ wasequal to 3.63 at $99.5 \%$ confidence level. The last column in Table 2 indicates the percentage contribution $(\% \mathrm{P})$ of each factor, thus exhibiting the level of influence on the quality characteristic. Results shows that the thickness of plate, tool tapper angle, lubrication, feed rate and tool rotation speed have percentage contributions of $39.49 \%, 8.48 \%, 16.48 \%, 13.38 \%$ and $2.67 \%$ respectively on tensile strength of the specmen.

\section{CONCLUSIONS}

The effects of process parameters on FSHE were studied. Taguchi and ANOVA methods were applied to investigate the effects of thickness of plate, tool taper angle, lubrication rate, feed rate and tool rotational speed. Micro structural studies showed that division of the grains depend upon the forming parameters in the given direction. Micro structural studies showed that the changes in flow direction of grains were observed along with the banding of the grains. The optimum test condition at which the UTS was obtained, was determined to be A1B3C1D2E3 levels.

\section{REFERENCES}

1. G. V. Dunchev, J. T. Maximov and N. Ganev, "A new conception for enhancement of fatigue life of large number of fastener holes in aircraft structures, Fatigue and Fracture of Engineering Materials and Structures”, June 2016

2. Azushima, A., Koop, R., Korhonen, A., Yang, D. Y., Micari, F., Lahoti, G. D., Groche, P., Yanagimoto, J., Tsuji, N., Rosochowski, A. and Yanadida, A. (2008) Severe plastic deformation (SPD) process for metals. CIRP Annals - Manuf. Technol., 57, 716-735..

3. Aayush Bawdekar et al.,, Surface Hardening and Microstructural Evolution of High Carbon Steel By Friction Stir Processing, International Journal of Mechanical and Production Engineering Research and Development (IJMPERD), Volume 7, Issue 3, May - June 2017, pp. 343-354

4. Valiev, R. Z., Islamgaliev, R. K. and Alexandrov, I. V. (2000), "Bulk nanostructured materials from severe plastic deformation", Program. Material Science, 45, 103-189.

5. M. M. Siva et al., Effect of Microstructure and Hardness Properties of Al2011 based Composites for Titanium Di Boride using Stir Casting Method, International Journal of Mechanical and Production Engineering Research and Development (IJMPERD), Volume 7, Issue 2, March - April 2017, pp. 187-200

6. Shamdani, A. H. and Khoddam, S. (2012), “A comparative numerical, study of combined cold expansion and local torsion of fastener holes. Fatigue Fracture Engineering Material Structure”, 35, 918-928.

7. Christ, R. J., Nardiello, J. A., Papazian, J. M. and Madsen, “J. S. Device and method for sequentially cold working and 
reaming a hole”, USA Patent 7770276

8. Panaskar, N. J. and Sharma, "ASurface modification an nanocomposite layering of fastener hole through friction stir processing”, Material Manufacturing Processes, 29, 726-732,. (2014) 
